\title{
Benign Choroid Neoplasm
}

National Cancer Institute

\section{Source}

National Cancer Institute. Benign Choroid Neoplasm. NCI Thesaurus. Code C3625.

A non-metastasizing neoplasm that arises from the choroid. 